\title{
Class-E Amplifier Design Improvements for GSM Frequencies
}

\author{
Z. Nadir* and F. Touati \\ Department of Electrical and Computer Engineering, College of Engineering, Sultan Qaboos University, P.O. Box 33,
} P.C. 123, Al-Khodh, Muscat, Sultanate of Oman

Received 8 September 2009; accepted 8 September 2010

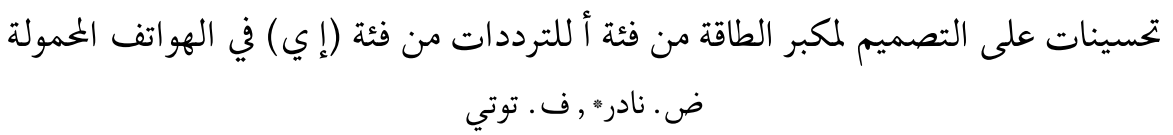

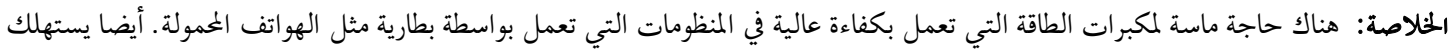

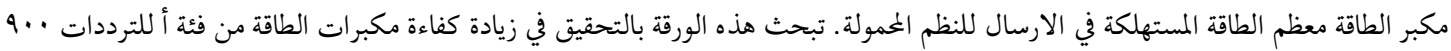

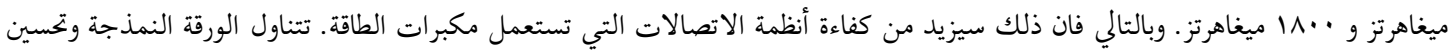

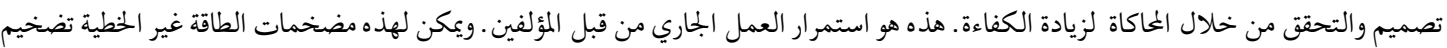

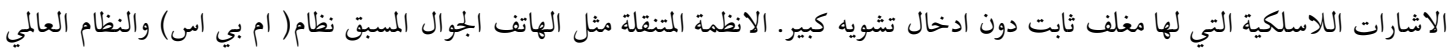

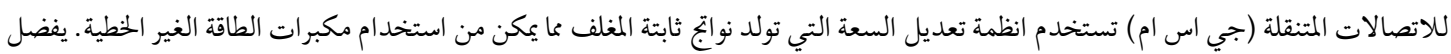

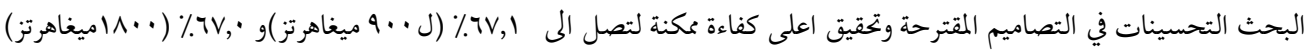

$$
\text { المفردات المفتاحية: مكبرات الطاقة من فئة أ، مكبر الطاقة المتحول، الكفاءة العالية: الشبكة المطابقة، وخسائر التحويل }
$$

\begin{abstract}
Efficient power amplifiers are essential in portable battery-operated systems such as mobile phones. Also, the power amplifier (PA) is the most power-consuming building block in the transmitter of a portable system. This paper investigates how the efficiency of the power amplifier (which is beneficial for multiple applications in communcation sector) can be improved by increasing the efficiency of switching mode class E power amplifiers for frequencies of $900 \mathrm{MHz}$ and $1800 \mathrm{MHz}$. The paper tackles modeling, design improvements and verification through simulation for higher efficiencies. This is the continuation of previous work by the authors. These nonlinear power amplifiers can only amplify constant-envelope RF signals without introducing significant distortion. Mobile systems such as Advanced Mobile Phone System (AMPS) and Global System for Mobile communications (GSM) use modulation schemes which generate constant amplitude RF outputs in order to use efficient but nonlinear power amplifiers. Improvements in designs are suggested and higher efficiencies are achieved, to the tune of $67.1 \%$ (for $900 \mathrm{MHz}$ ) and $67.0 \%(1800 \mathrm{MHz}$ ).
\end{abstract}

Keywords: Class-E power amplifiers, Switching mode amplifier, High efficiency, Matching network, Switching losses

\section{Introduction:}

The expensive development of wireless communication systems during the last decade has particularly put the design of Radio Frequency Power Amplifiers in focus. In general, a power amplifier is designated as the last amplifier in a transmission chain as shown in Fig. 1. It is the amplifier stage that typically requires the most attention to power efficiency. Handsets are battery-operated devices and their talk-time will directly depend on the efficiency of the power amplifier. Efficiency and linearity are opposing requirements in the power amplifiers design and much research is focused on how to improve the efficiency

\footnotetext{
*Corredsponding author's e-mail: nadir@squ.edu.om
} 


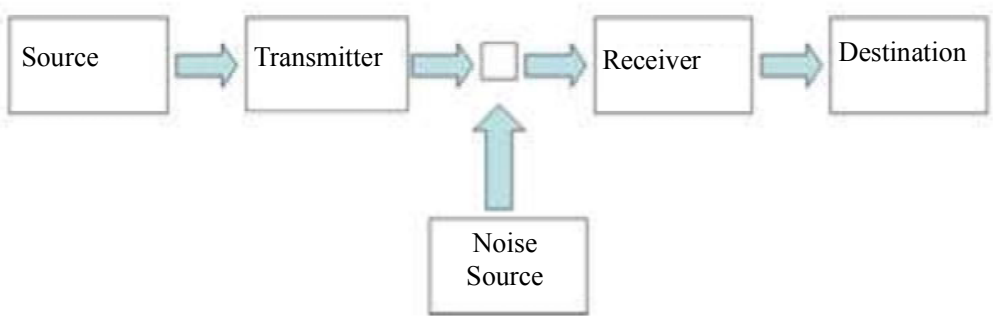

Figure 1. Classic architecture of a transmission channel

of power amplifiers circuits while still satisfying the linearity requirements of a given system (Su. et al. 1998 and Lee et al. 2004).

The need for linear power amplifiers arises in many radio frequency applications. SDR, cognitive radio etc. At present, most linear power amplifiers designed for portable devices, employ a class A output stage and exhibit efficiencies around $30 \%$ to $40 \%$ (B. Razafi et al. 1998). To achieve a higher efficiency, it is possible to begin with a nonlinear power amplifier and apply linearization techniques to the circuit.

This paper focuses on improving the efficiency of class-E power amplifiers by reducing the switching losses. The approach proposes a better biasing section of the transistor for a faster switching and optimizes the power transferred to the load through a well-optimized matching network.

\section{Theory and System Design}

Sokal was the first to introduce the highly efficient Class-E amplifier (Sokal et al. 1975) which achieve significantly higher efficiency than conventional Class $\mathrm{B}$ or $\mathrm{C}$ amplifiers which represents an attractive solution for portable radio devices enabling longer operation times. The power consumed by the transistor is low during the RF period because of switching transitions which are an effective part in meeting high-efficiency requirements. Designers make on/off switching transitions as fast as practical with high efficiency techniques which must be accommodated. The high voltage -current product during the switching transitions can also be avoided by using the following strategies:

1. The rise of transistor voltage is delayed until the current is reduced to zero.

2. The transistor voltage returns to zero before the current begins to rise.

As a result, waveforms of the high voltage and high current never exist simultaneously (Berglund et al. 2006).

\subsection{Design Analysis at $900 \mathrm{MHz}$}

Figure 2 shows the basic circuit of a class E power amplifier where the AMS CMOS $0.35 \mu \mathrm{m}$ process transistor parameters are used (Nadir et al. 2009). The circuit is the basic topology of a class E power amplifier circuit which comprises a switch (ie. transistor $\mathrm{M1}$ ), a grounded capacitor $\mathrm{C}_{2}$, and a series network $\mathrm{C}_{1}$ and $\mathrm{L}_{2} . \mathrm{L}_{1}$, which is the radio-frequency choke (RFC). It has high impedance at the frequency of operation and $\mathrm{C}_{2}$ includes the drain junction capacitance of M1. The values of $\mathrm{C}_{1}, \mathrm{C}_{2}, \mathrm{~L}_{2}$, and $\mathrm{R}_{\mathrm{L}}$ are selected such that the power switching losses of M1 are reduced, which would increase the power efficiency. We assume the following: a center frequency, $f_{\mathrm{o}}=900 \mathrm{MHz}, \mathrm{P}_{\text {out }}=$ $20 \mathrm{~dB}_{\mathrm{m}}(100 \mathrm{~mW})$ which is available across the load resistor, $\mathrm{V}_{\mathrm{cc}}=2.5 \mathrm{~V}$ (the power supply) and $\mathrm{R}_{\mathrm{L}}=50$ $\Omega$, which is considered as antennas input impedance. For optimum power of a class E power amplifier, the optimum resistance, $\mathrm{R}_{\text {Lopt }}$ comes out as (Lee et al. 2004):

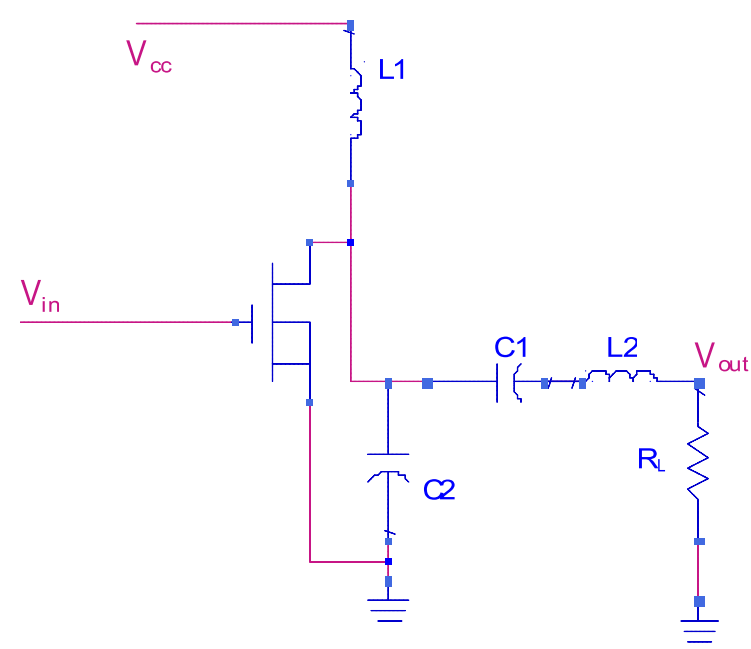

Figure 2. Basic circuit of class $\mathbf{E}$ power amplifier 


$$
\begin{aligned}
& P_{\text {out }}=\frac{2}{1+\frac{\pi^{2}}{4}} \frac{V_{c c}^{2}}{R_{\text {Lopt }}}=\frac{0.577 V_{c c}^{2}}{R_{\text {Lopt }}} \\
& R_{\text {Lopt }}=36.06 \Omega
\end{aligned}
$$

$\mathrm{R}_{\mathrm{L}}$ should be down-converted from $50 \Omega$ to 36.06 $\Omega$ using a matching network as shown in Fig. 3 for optimum power delivery.
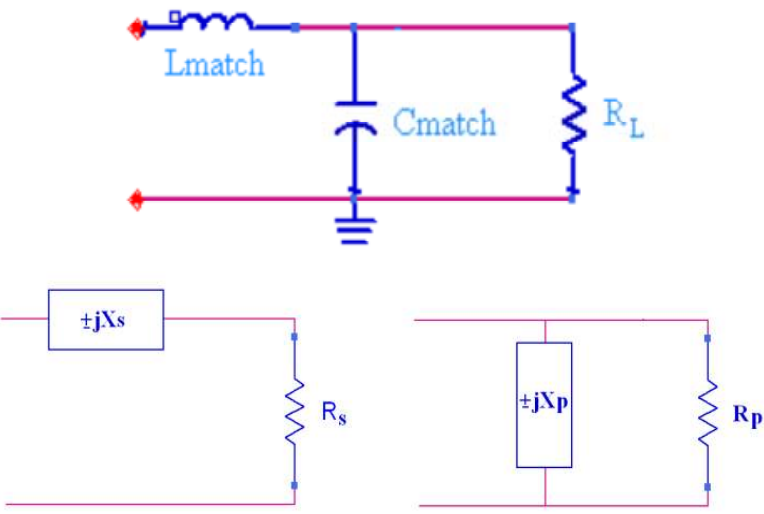

Figure 3. Down convert matching network

Where,

$$
\begin{array}{ll}
R_{s}=\frac{R_{p} X_{p}{ }^{2}}{R_{p}{ }^{2}+X_{p}{ }^{2}} & X_{s}=\frac{R_{p}{ }^{2} X_{p}}{R_{p}{ }^{2}+X_{p}{ }^{2}} \\
R_{p}=\frac{R_{s}{ }^{2}+X_{s}{ }^{2}}{R_{s}} & X_{p}=\frac{R_{s}{ }^{2}+X_{s}{ }^{2}}{X_{s}} \\
X_{p}=\frac{1}{\omega_{o} C_{\text {match }}} & X_{s}=\omega_{o} L_{\text {match }}
\end{array}
$$

To convert $50 \Omega$ to $36.06 \Omega$, let us use $\mathrm{R}_{\mathrm{s}}=36.06 \Omega$ and $\mathrm{R}_{\mathrm{p}}=50 \Omega$ So:

$$
\begin{gathered}
\omega_{\mathrm{o}}=2 \pi f_{\mathrm{o}}=5.65 \times 10^{9} \mathrm{rad} / \mathrm{s} \\
R_{s}=\frac{R_{p} X_{p}^{2}}{R_{p}^{2}+X_{p}^{2}}=36.06 \Omega \\
X_{p}=80.38 \text { for } \mathrm{R}_{\mathrm{p}}=50 \Omega \\
C_{\text {match }}=\frac{1}{\omega_{o} X_{p}}=2.2 p F \\
X_{s}=\frac{R_{p}^{2} X_{p}}{R_{p}^{2}+X_{p}^{2}}=22.42 \Omega
\end{gathered}
$$

$$
L_{\text {match }}=\frac{22.42}{5.65 \times 10^{9}}=3.97 n H
$$

The total input impedance looking from the left of the circuit shown in Fig. 3 is:

$Z_{\text {total }}=\frac{R_{L}-\omega^{2} R_{L} C_{\text {match }} L_{\text {match }}+j \omega L_{\text {match }}}{j \omega R_{L} C_{\text {match }}+1}$

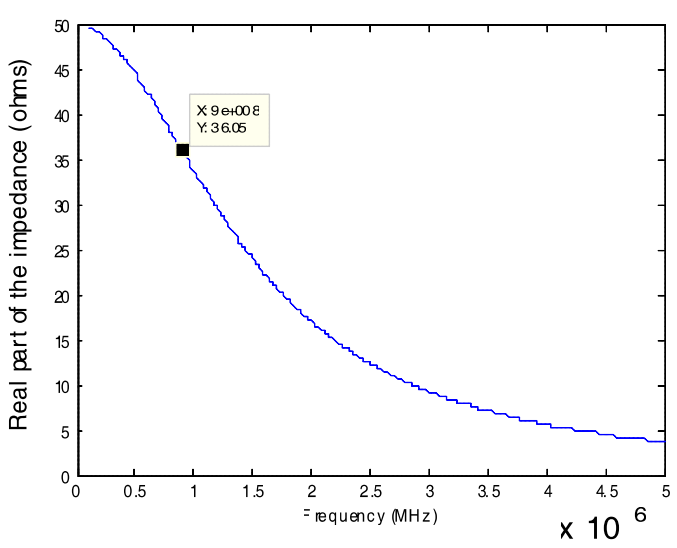

(a)

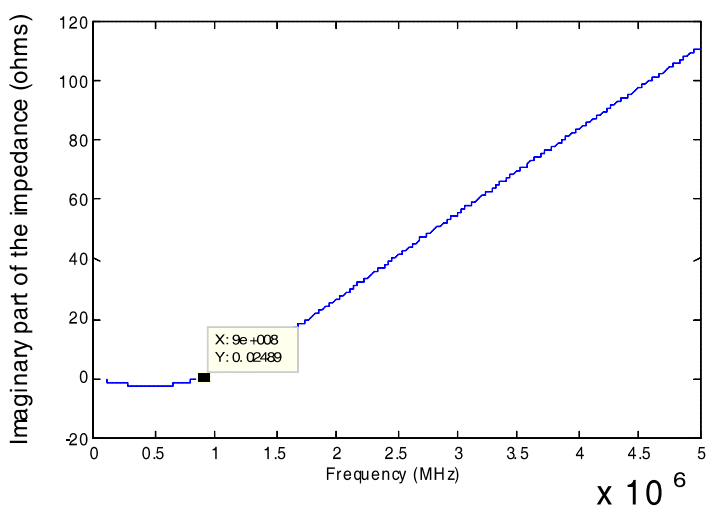

(b)

Figure 4. (a) Real and (b) Imaginary parts of $t$ he impedance against ffrequency at 900 MHz

As can be seen, for a frequency of $900 \mathrm{MHz}$, the real part of the impedance is $36.05 \Omega$ whereas the imaginary part is $0.02489 \Omega$ which justifies our previous calculations. Theoretically the higher the value of $\mathrm{Q}$, the better in terms of selectivity, but since a higher value of $Q$ requires a larger inductor this is not preferable for portable radio devices because size is a major issue. The quality factor (or Q) of an inductor is the ratio of its inductive reactance to its resistance at a 
given frequency, and is a measure of its efficiency. The $\mathrm{Q}$ factor is a widespread measure used to characterize resonators. It is defined as the peak energy stored in the circuit divided by the average energy dissipated in it per cycle at resonance. Low Q circuits are therefore damped and lossy and high $Q$ circuits are under-damped. As Q is related to bandwidth; low Q circuits are wide band and high $\mathrm{Q}$ circuits are narrow band. In our case, quality factor for the series resonance branch $\left(\mathrm{C}_{1}, \mathrm{~L}_{2}\right)$, as shown in Fig. 2 , is assumed as 5 for a reasonable-sized inductor. It follows that:

$$
\begin{gathered}
C_{2}=\frac{1}{\omega_{o} R_{L}\left(\frac{\pi^{2}}{4}+1\right)\left(\frac{\pi}{2}\right)}=\frac{1}{\omega_{o}\left(5.447 R_{L}\right)}=0.9 p F \\
L_{2}=\frac{Q R_{L}}{\omega_{o}}=31.9 n H \\
C_{1}=C_{2}\left(\frac{5.447}{Q}\right)\left(1+\frac{1.42}{Q-2.08}\right)=1.46 p F
\end{gathered}
$$

$\mathrm{L}_{1}$ is chosen to be $30 \mathrm{uH}$ since it must have a sufficiently large impedance at the center frequency. Table-1 summarizes the designed reactive elements of the matching network for $900 \mathrm{MHz}$ and $1800 \mathrm{MHz}$ networks (similar design steps are carried out for $850 / 1900 \mathrm{MHz}$ circuits but is not shown in the current paper).

Table 1. Summary of the designed passive components for the class $E$ power amplifier and $1800 \mathrm{MHz}$

\begin{tabular}{|c|c|c|}
\hline $\begin{array}{c}\text { Designed } \\
\text { Passive } \\
\text { Components }\end{array}$ & $\mathbf{9 0 0} \mathbf{~ M H z}$ & $\mathbf{1 8 0 0} \mathbf{~ M H z}$ \\
\hline $\mathrm{M}_{\text {atch }}$ & $2.20 \mathrm{pF}$ & $1.10 \mathrm{pF}$ \\
\hline $\mathrm{M}_{\text {atch }}$ & $3.97 \mathrm{nH}$ & $1.98 \mathrm{nH}$ \\
\hline $\mathrm{C}_{1}$ & $1.46 \mathrm{pF}$ & $0.73 \mathrm{pF}$ \\
\hline $\mathrm{C}_{2}$ & $0.90 \mathrm{pF}$ & $0.45 \mathrm{pF}$ \\
\hline $\mathrm{L}_{1}$ & $30.00 \mathrm{uH}$ & $30.00 \mathrm{uH}$ \\
\hline $\mathrm{L}_{2}$ & $31.90 \mathrm{nH}$ & $15.94 \mathrm{nH}$ \\
\hline
\end{tabular}

\section{Design Procedure and Results Discuss- ion}

Simulation is done for a class E power amplifier for both frequencies $900 \mathrm{MHz}$ and $1800 \mathrm{MHz}$ (Dhawyani et al. 2008).

\subsection{Design Results for $900 \mathrm{MHz}$ and 1800 $\mathrm{MHz}$}

Figure. 5 shows the circuit of a class E power amplifier (only for $900 \mathrm{MHz}$ is shown). A sinusoidal input with an amplitude of $1 \mathrm{~V}$, at $900 \mathrm{MHz}$, is considered.
The results show that the output power which is causing low efficiency needs to be improved. These are clearly shown through the graphs. The time delay as visible in graphs suggests faster switching. We focused on improving the efficiency of class-E power amplifiers by reducing the switching losses. The approach proposes a better biasing section of the transistor for a faster switching and optimizes the power transferred to the load through a well-optimized matching network.

\subsection{Re-designed Circuits for 900 and $1800 \mathrm{MHz}$}

Improved topologies of the circuit in Fig. 5 are shown in Figs. 12 and 13. However Fig. 14 mentions the process of biasing for fast transition.

The resistors $4 \mathrm{~K} \Omega$ and $2 \mathrm{~K} \Omega$, as shown in Figs. 12 and 13 , bias the transistor in the sub-threshold region. This is simply a voltage division procedure adopted to bias the transistor at sub-threshold region. This makes the transistor switch even for a small increment of the input ac signal and hence fosters faster switching. Better transitions were obtained as shown in following Figs. 15 to 20.

These results show the response of PAs in order to observe the switching losses. These faster transitions reduced the switching losses and hence improved the power efficiencies.

Table. 2 summarizes the results of the basic and improved circuits for the two frequencies of $900 \mathrm{MHz}$ and $1800 \mathrm{MHz}$ of interest. The efficiency of a power amplifier is calculated below:

The supply power Figure:

$\left(\mathrm{P}_{\mathrm{DC}}\right)=\mathrm{I}_{\mathrm{DC}} \quad \mathrm{V}_{\mathrm{DC}}$

$\mathrm{P}_{\mathrm{d}}$ (drain power $)=34.9 \mathrm{~mA} \quad 2.5 \mathrm{~V}=87.25 \mathrm{~mW}$

Average output power obtained from Fig. 12 is:

$$
\begin{gathered}
\operatorname{Efficency}(\eta)=\frac{P_{\text {outavg }}}{P_{\text {in }}+P_{D C}} \\
\mathrm{P}_{\text {outavg }}=56.3 \mathrm{~mW}
\end{gathered}
$$

The average input power $\mathrm{P}_{\text {in }}$ is in $\mathrm{uW}$ range which is very small compared to $\mathrm{P}_{\mathrm{DC}}$ and is therefore ignored.

$$
\eta=\frac{56.3 m W}{87.25 m W} \times 100=64.5 \%
$$

Similar steps are used for calculating efficiencies for other circuits at different frequencies.

For maximum power transfer, matching networks were also designed at the input of the amplifier. Without a proper matching network, a significant amount of power will be lost. The addition of a proper value of inductor to the source of the switching tran- 


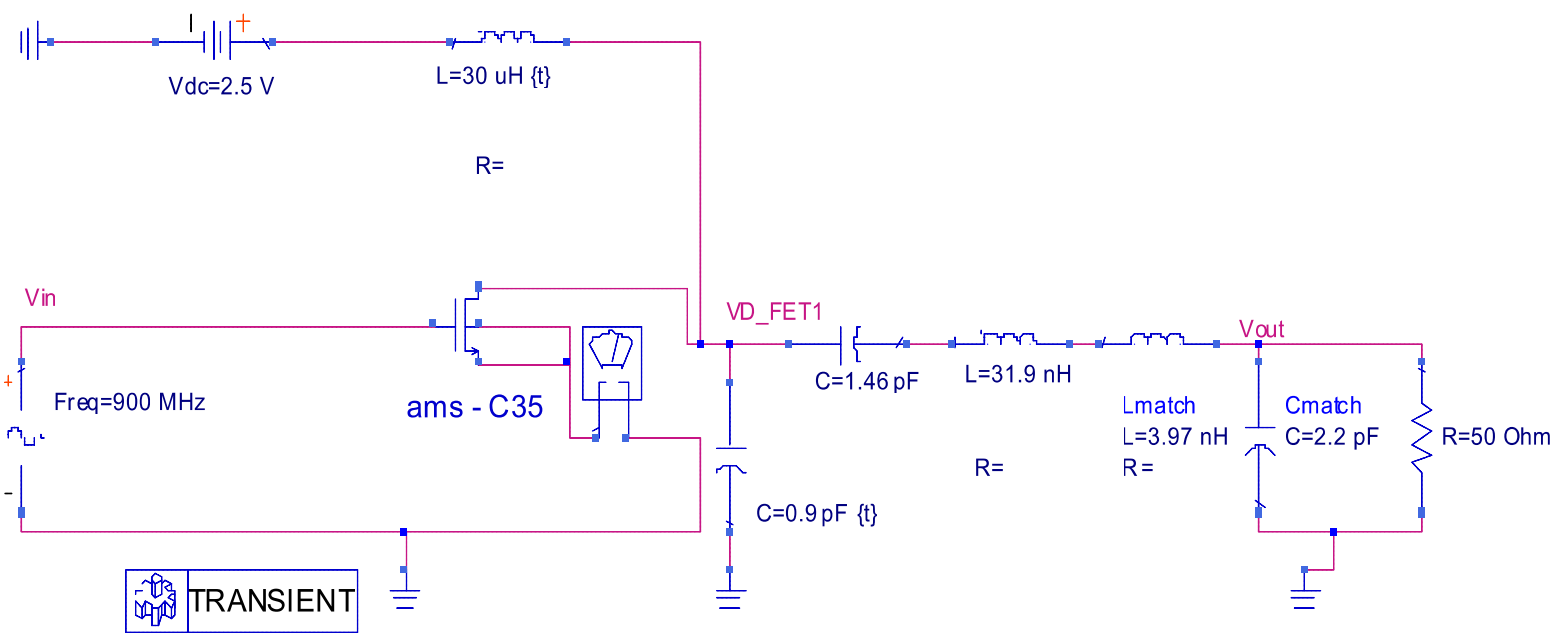

Figure 5. Class E power amplifier at $900 \mathrm{MHz}$

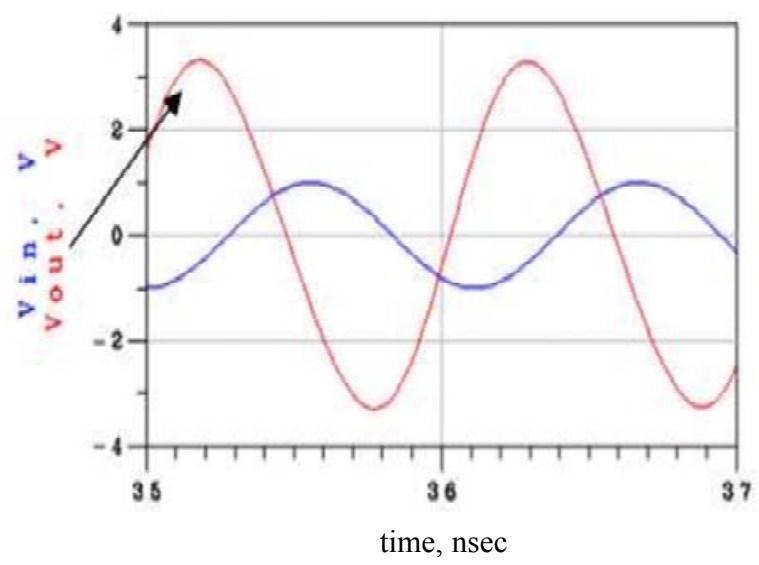

Figure 6. Input voltage $\left(V_{\text {in }}\right)$ and amplified output voltage $\left(V_{\text {out }}\right)$ at $900 \mathrm{MHz}$

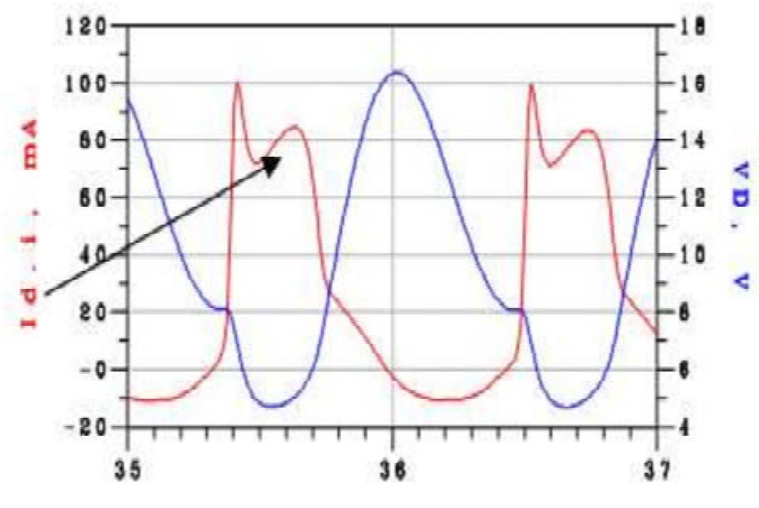

time, nsec

Figure 7. Drain current $\left(I_{d}\right)$ and drain voltage $\left(V_{D}\right)$ across the transistor at $900 \mathrm{MHz}$

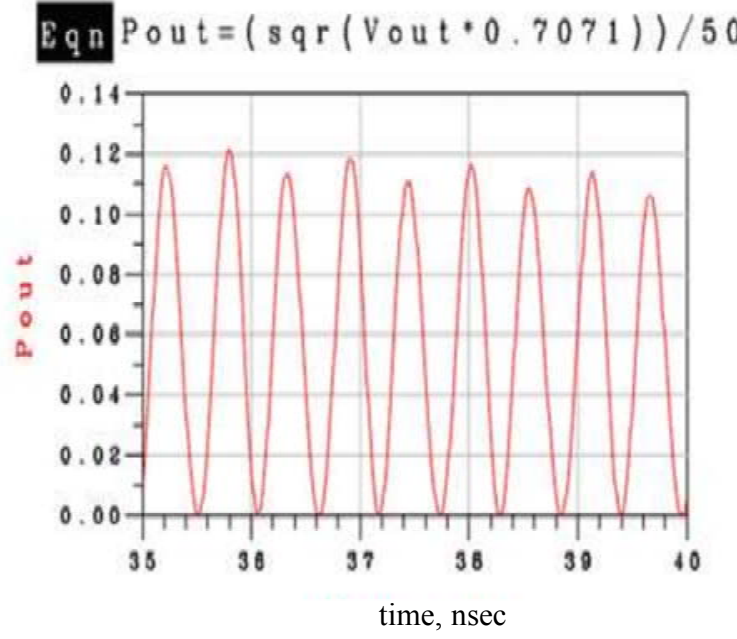

Figure 8. Output power (W) for the basic circuit at $900 \mathrm{MHz}$

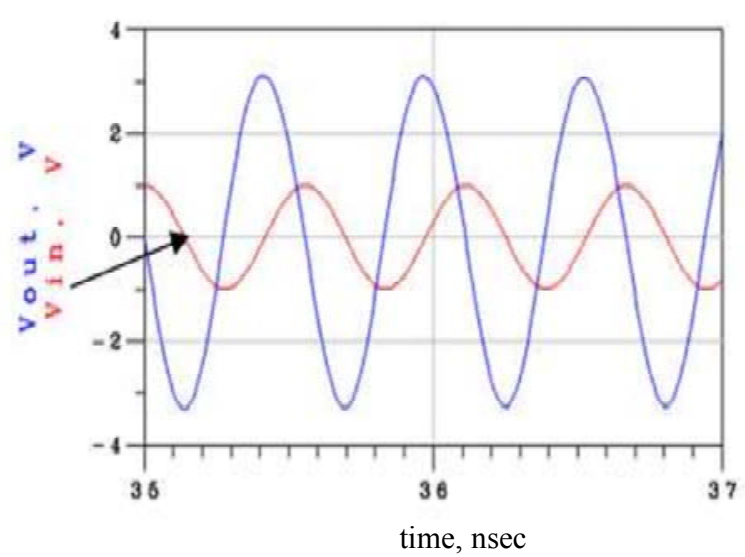

Figure 9. Input voltage $\left(V_{\text {in }}\right)$ and amplified output voltage ( $\left.V_{\text {out }}\right)$ at $1800 \mathrm{MHz}$ 


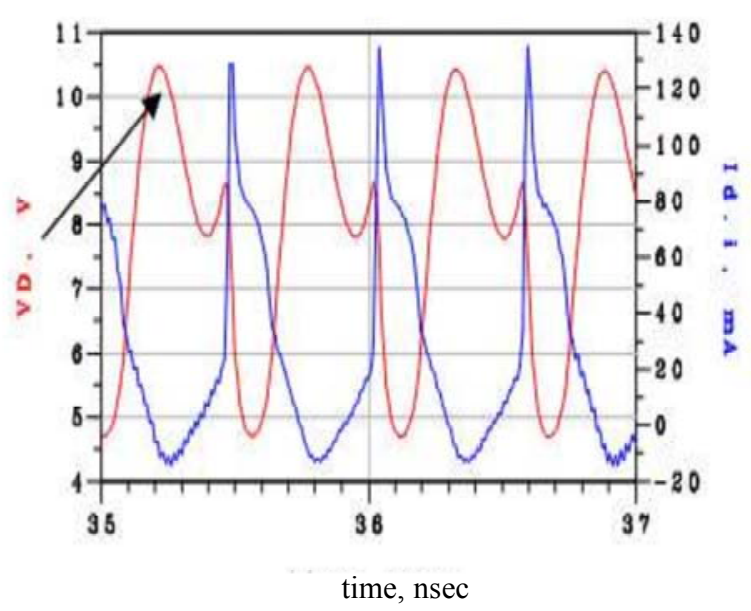

Figure 10. Drain current ( $\left.I_{d}\right)$ and drain voltage $\left(V_{D}\right)$ across the transistor at 1800 MHz

\section{EqnPout $=\operatorname{sqr}(\mathrm{rms}(\mathrm{Vout})) / 50$}

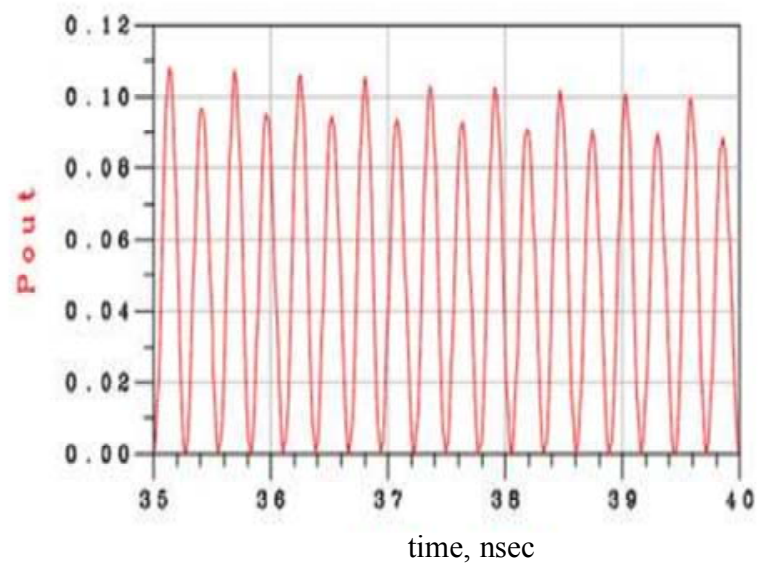

Figure 11. Output power (W) for the basic circuit at $1800 \mathrm{MHz}$

Table 2. Summary of the efficiency

\begin{tabular}{|c|c|c|}
\hline $\begin{array}{l}\text { Frequency } \\
\text { (MHz) }\end{array}$ & Basic Circuit & $\begin{array}{l}\text { Modified } \\
\text { Circuit }\end{array}$ \\
\hline 900 & $64.5 \%$ & $67.1 \%$ \\
\hline 1800 & $56.1 \%$ & $67.0 \%$ \\
\hline
\end{tabular}

sistor makes the input resonant at $900 \mathrm{MHz}$ or 1800 $\mathrm{MHz}$. The value of $30 \mathrm{uH}$ is a reasonable value considering also the current technology limitations. However, that tuning inductor makes the current switching of the transistor slower and hence decreases the efficiency. Techniques on how to keep the input of the amplifier matched to the source during fast switching are under investigation. Initial results have been encouraging. The matching is an issue to be addressed for maximum power transfer thus increasing efficiency. A PAE of around $41 \%$ was achieved at $900 \mathrm{MHz}$ ( Yoo et al. 2001). Also, the drain efficiency was observed around $40 \%$ and $45 \%$ for $900 \mathrm{MHz}$ and $1800 \mathrm{MHz}$ bands respectively (Larcher et al. 2009). The objectives of design improvements for higher efficiency of PAs at $900 \mathrm{MHz}$ and $1800 \mathrm{MHz}$ were achieved. These results will be used for further verifications and also for other bands of GSM frequencies which are out of the scope of the current paper.

\section{Conclusions}

The class E power amplifier were designed and simulated for GSM frequencies of $900 \mathrm{MHz}$ and 1800 $\mathrm{MHz}$. The redesigned circuits show good improvement in efficiency compared to the efficiencies given by the basic circuits. The dissipated power in the transistors was high due to the transitions between the drain voltage and drain current which led to lower efficiencies. Although the figures for the drain voltages and currents for basic and redesigned circuits are less elaborate from visual point of view, the calculation showed significant improvement as tabulated above. Also, the use of a proper matching network at the output and better switching techniques achieved by redesigning the bias circuits for proper threshold voltages improved the amplifier efficiency at both frequencies. Simulated results show power efficiencies of $67.1 \%$ and $67 \%$ at frequencies of $900 \mathrm{MHz}$ and 1800 $\mathrm{MHz}$ respectively.

\section{Acknowledgment}

The authors would like to thank A. Kalbani, M. Dhawyani, Q. Mahrooqi, and F. Rahbi for their valuable contribution in carrying out the simulation tests and presenting some discussion of the results. The authors would also like to thank Sultan Qaboos University for the internal grant which helped in achieving the desired results.

\section{References}

Berglund, B., Johansson, J. and Lejon, T., 2006, "High Efficiency Power Amplifiers," Ericsson Review No. 3, pp. 92-96.

Dhawyani, M., Mahrooqi, Q., Rahbi, F., Kalbani, A., Touati, F. and Nadir, Z., 2008, "Improvement in the Efficiency of Class-E Power Amplifier for RF," IEEE 5th Int. Multi Conference on Systems, Signals and Devices, (SSD'08), pp. 491-495, Jordan. 


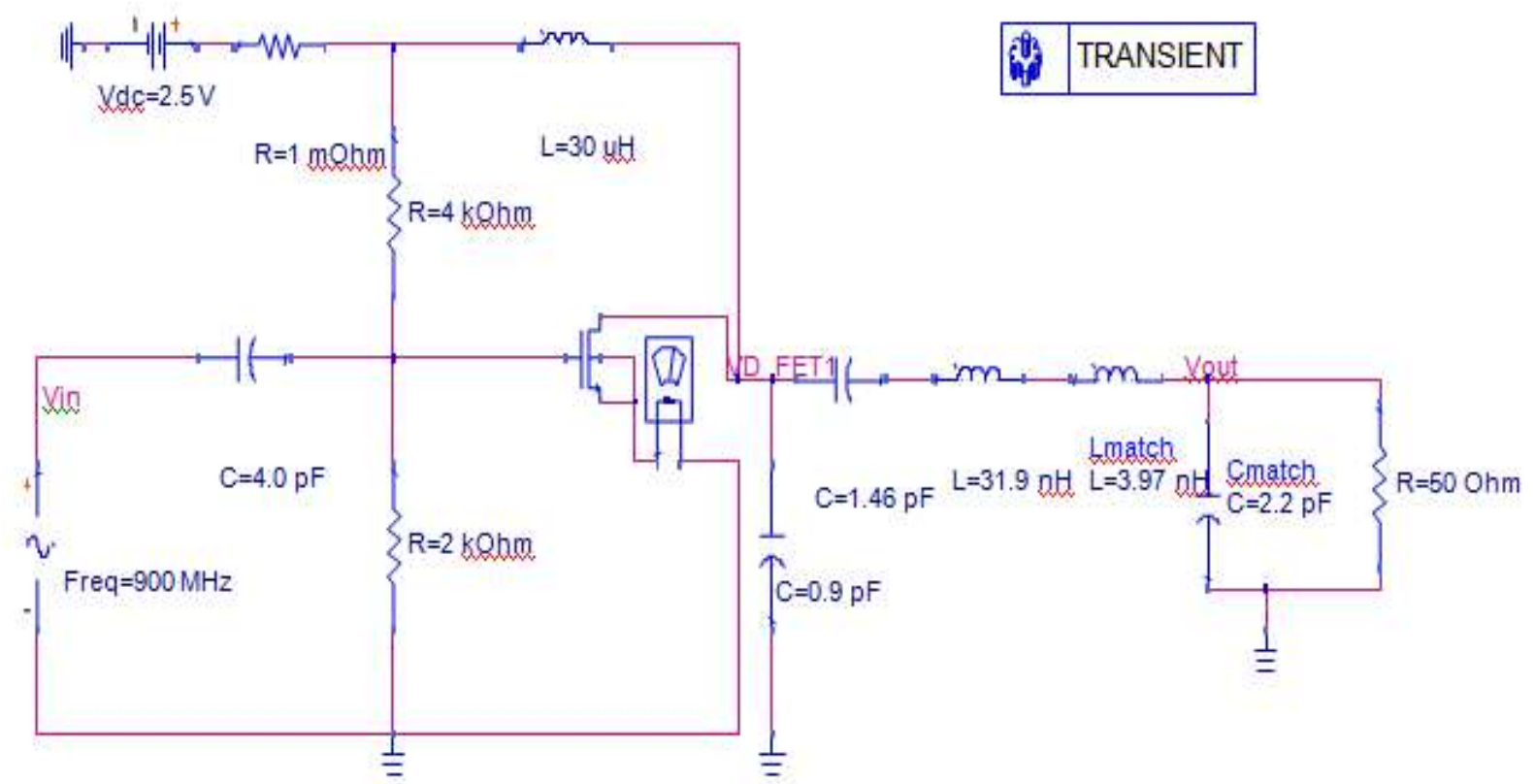

Figure 12. Improved circuit of class - E power amplifier at $900 \mathrm{MHz}$

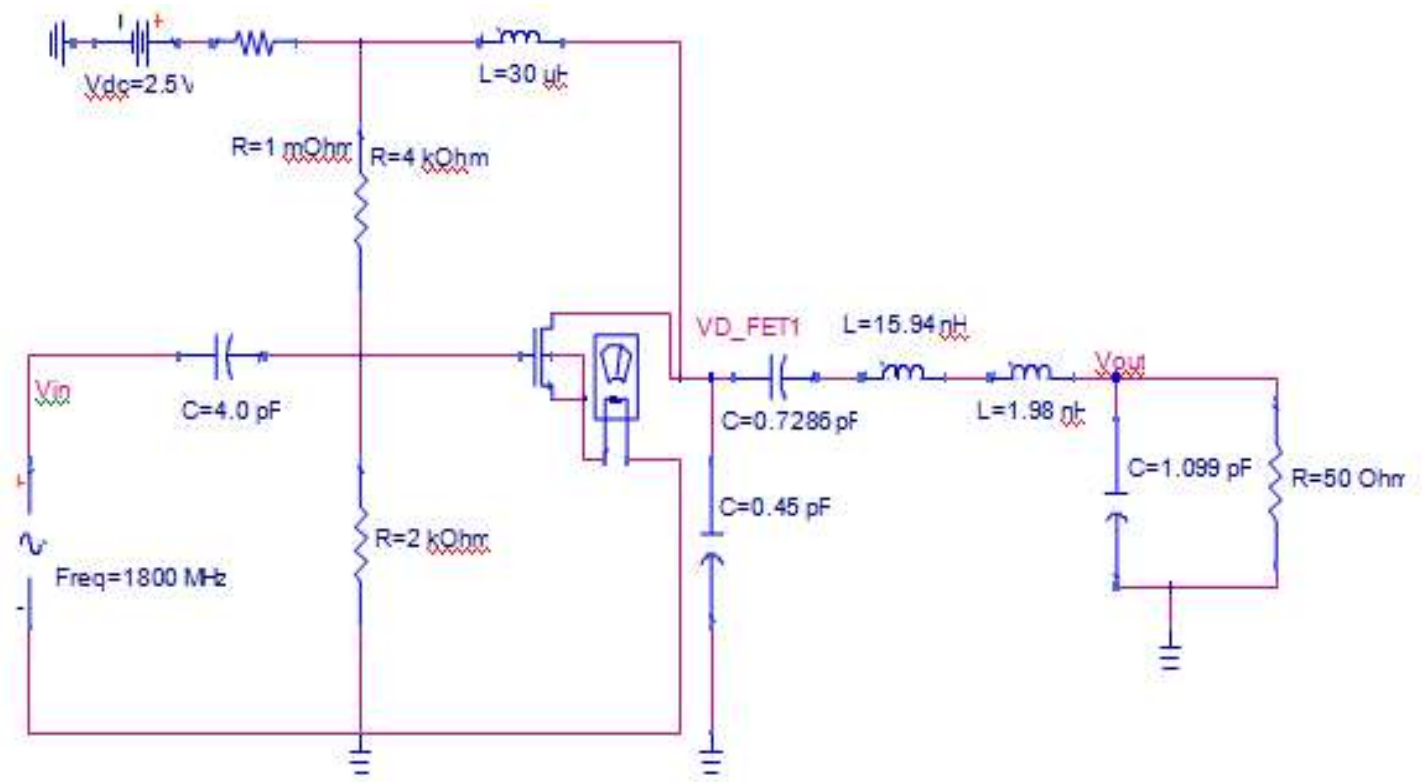

Figure 13. Improved circuit of class - E power amplifier at $1800 \mathrm{MHz}$

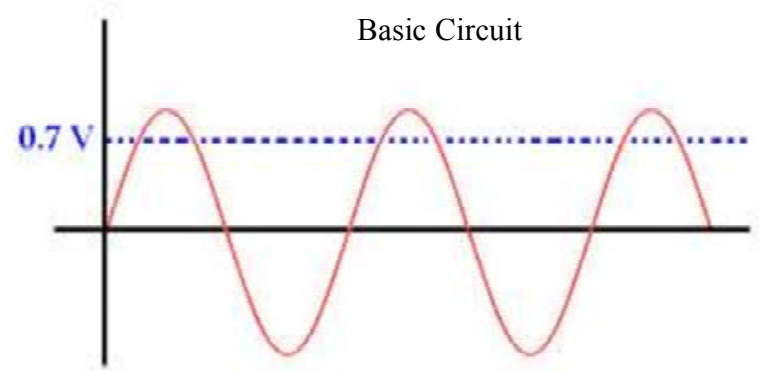

(a)

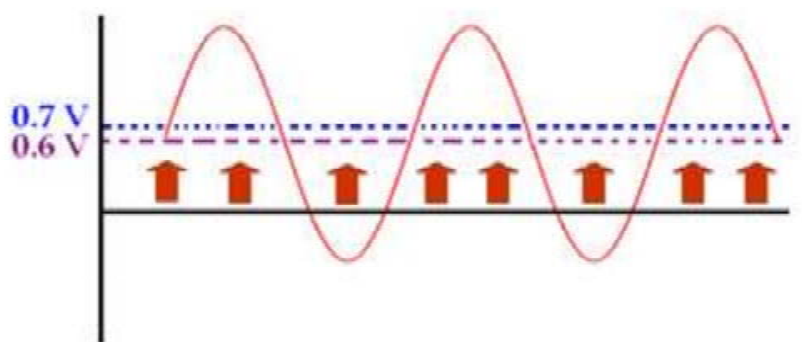

(b)

Figure 14. (a) The gate of source voltage $\left(V_{G S}\right)$ for basic circuit and (b) The gate to source voltage $\left(V_{G S}\right)$ for redesigned circuit $V_{s}$ time (sec) 


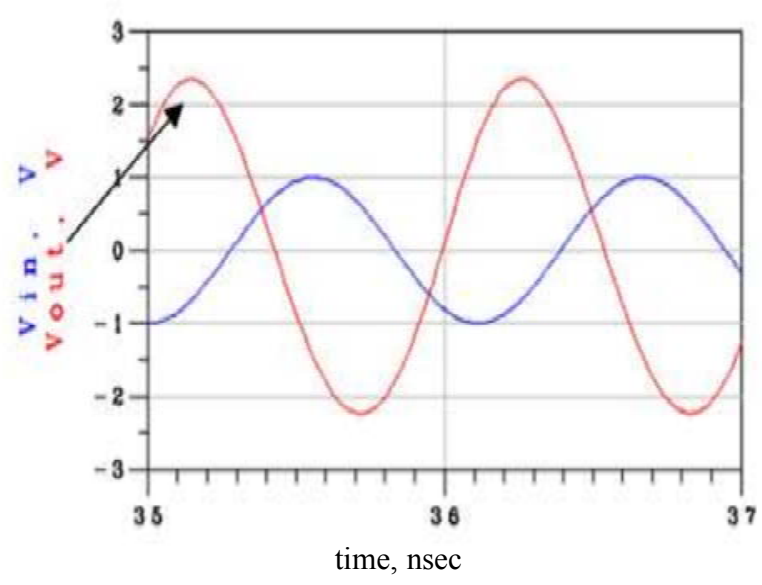

Figure 15. Input vltage ( $\left.V_{\text {in }}\right)$ and amplified output voltage $\left(V_{\text {out }}\right)$ of the redesigned circuit at $900 \mathrm{MHz}$

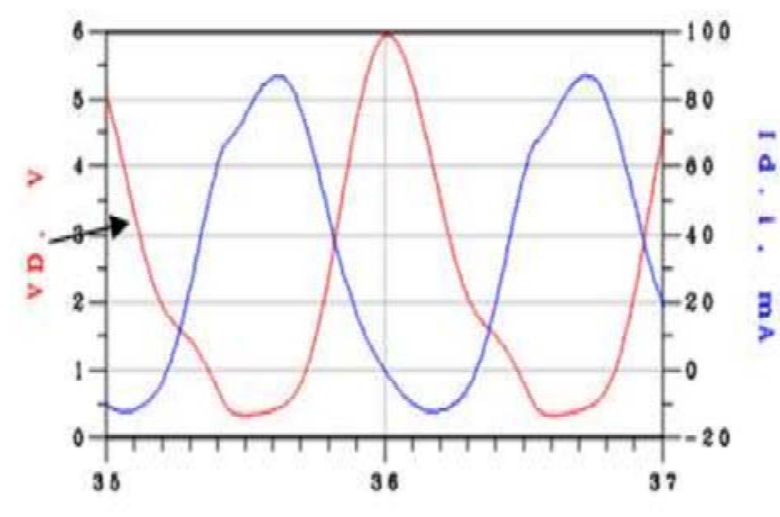

time, nsec

Figure 16. Drain current $\left(L_{d}\right)$ and drain voltage $\left(V_{D}\right)$ across the transistor (MNI) for the redesigned circuit at $900 \mathrm{MHz}$

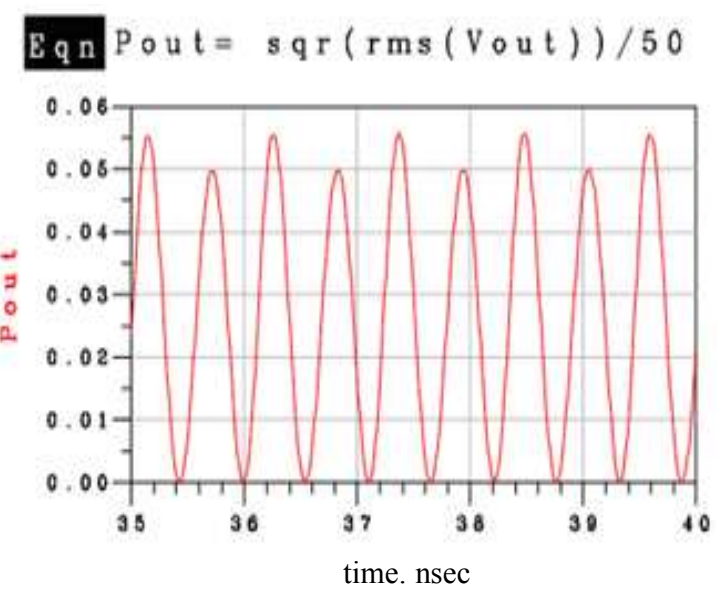

Figure 17. Output power (W) for the redesigned circuit at $900 \mathrm{MHz}$

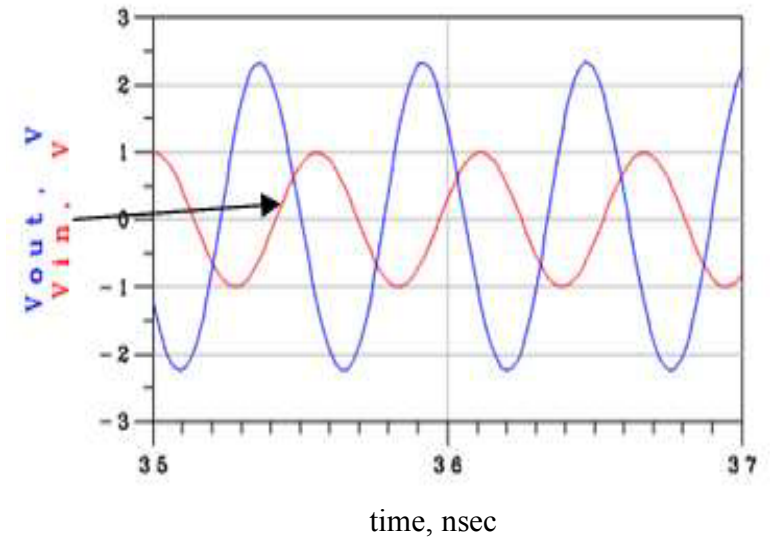

Figure 18. Input voltage $\left(V_{\text {in }}\right)$ and amplified output voltage $\left(V_{\text {out }}\right)$ of the redesigned circuit at $1800 \mathrm{MHz}$

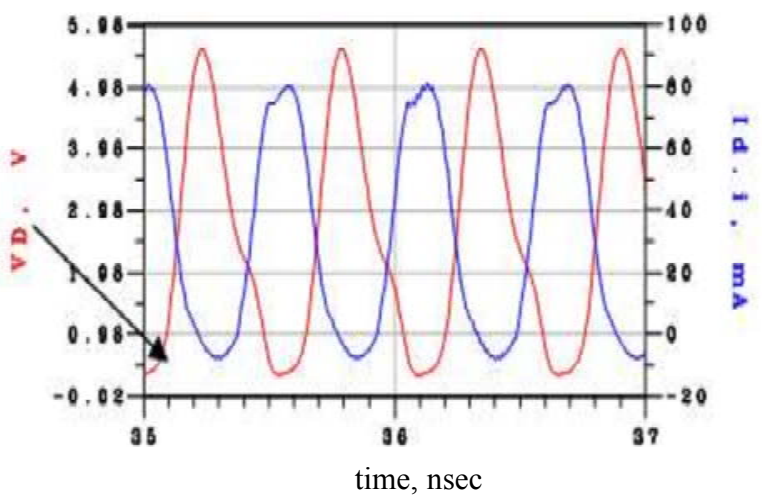

Figure 19. Drain current ( $I_{d}$ ) and drain voltage $\left(V_{D}\right)$ for the modified circuit at 1800 MHz

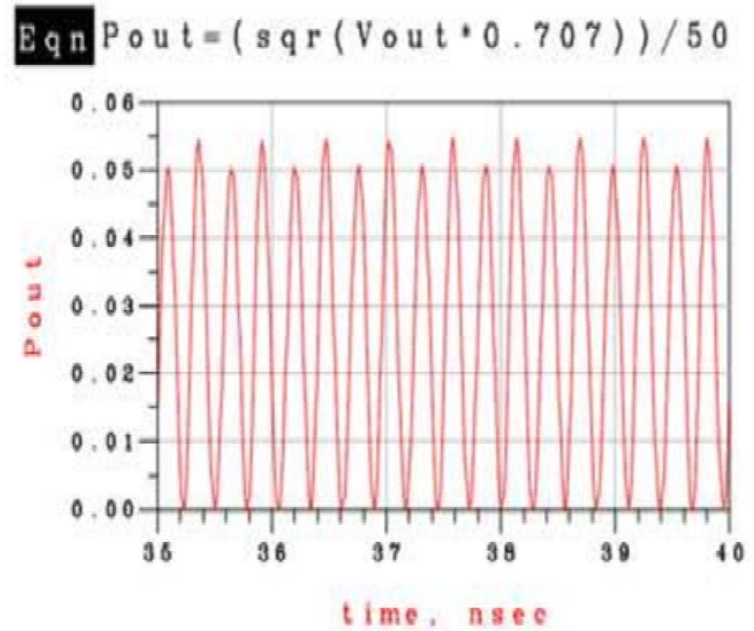

Figure 20. Output power $(\mathrm{W})$ for the redesigned circuit at $1800 \mathrm{MHz}$ 
Larcher, L., Brama, R., Ganzerli, M., Iannacci, J., Margesin, B., Bedani, M. and Gnudi, A., 2009, "A MEMS Reconfigurable Quad-Band Class E power amplifier for GSM Standard," IEEE 22nd Int. Conference on Micro Electro Mechanical Systems, (MEMS'09), pp. 864-867, Australia.

Lee, T., 2004, "The Design of CMOS RadioFrequency Integrated Circuits," ISBN 139780521835398, Cambridge University Press, UK.

Nadir, Z. and Touati, F., 2009, "Design of High Efficiency Switching Mode Power Amplifier for RF and Microwave," IEEE 16th Int. conference on Telecommunications (ICT'09), pp. 329-333, Morocco.
Razafi, B., 1998, "RF Microelectronics," ISBN:0-13887571-5, Prentice Hall, USA.

Sokal, N. and Sokal, A., 1975, "Class E-A New Class of High Efficiency Tuned Single-Ended Switching Power Amplifiers," IEEE J. Soild-State Circuits, Vol. 10(3), pp. 168-176.

Su, D. and McFarland, W., 1998, "An IC for Linearizing RF Power Amplifiers Using Envelope Elimination and Restoration," IEEE J. of Solid State Circuits, Vol 33(12), pp. 2252-2258.

Yoo, C. and Huang, Q., 2001, "A Common Gate Switched 0.9W Class E Power Amplifier with $41 \%$ PAE in 0.25- m CMOS," IEEE J. of Solid State Circuits, Vol. 36(5), pp. 823-830. 